\title{
FIELD EXPERIMENTAL INVESTIGATIONS OF PERFORMANCE-AND- TECHNOLOGICAL INDICATORS OF OPERATION OF SWATH HEADER ASYMMETRIC MACHINE-AND-TRACTOR AGGREGATE
}

\author{
Volodymyr Bulgakov ${ }^{1}$, Volodymyr Nadykto ${ }^{2}$, Hryhorij Kaletnik ${ }^{3}$, Semjons Ivanovs ${ }^{4}$ \\ ${ }^{1}$ National University of Life and Environmental Sciences of Ukraine, Ukraine; \\ ${ }^{2}$ Tavria State Agrotechnological University, Ukraine; \\ ${ }^{3}$ Vinnytsia National Agrarian University, Ukraine; \\ ${ }^{4}$ Latvia University of Life Sciences and Technologies, Latvia \\ semjons@apollo.lv
}

\begin{abstract}
An important problem of aggregating trailed asymmetrically arranged harvesting machines is unsatisfactory stability of their movement in a horizontal plane. The task of this investigation was to increase the performance-and-technological indicators of an asymmetric swath header machine-and-tractor aggregate by selecting its optimal kinematic and design parameters. The results of the conducted experimental studies made it possible to establish that at zero values of setting the angles of the supporting wheels of the trailed swath header to the direction of its movement its deviations in a horizontal plane are maximal. When the supporting wheels of the swath header are set at the angles of $8^{\circ}$ to the direction of its movement, the left supporting wheel is placed to the left of the trailed device at a distance of $0.2 \mathrm{~m}$, the bracket of the left wheel is additionally loaded with a mass of $1.0 \mathrm{kN}$, then the swath header in the aggregate with a wheeled tractor moves in a horizontal plane practically without any deviations. In contrast to the factory-made option, this provides an increase in the operating width by $5.1 \%$, and efficiency - by $7.0 \%$.
\end{abstract}

Keywords: swath, header, experiment, parameters, deviation.

\section{Introduction}

Two-phase harvesting of grain crops presupposes cutting the crop into swaths at the phase of wax ripeness of the grain and then (after its full ripening) threshing of the mass with combine harvesters. Application of the two-phase method of harvesting cereals is widely spread in some climatic zones (including in Ukraine), and it is particularly efficient for humid and unevenly ripening plants, etc. It has been established by investigations that this method of harvesting eared and leguminous crops allows to increase the efficiency of the harvesting machinery by at least $20 \%$ when picking swaths, to reduce by at least $25 \%$ the losses of grain due to its proper fall-off, and to ensure optimum loading of the combine harvester [1-5]. On the whole, to the positive qualities of the two-phase technology belong more uniform ripening, improved grain quality, reduced losses due to the seed fall to 2-3\%. It is most efficient, when the fields are highly contaminated with weeds in biological agriculture, with large amounts of work that do not allow harvesting quickly and without seed fall by means of the available harvesters, etc. The disadvantage of the technology is higher consumption of the diesel fuel. Therefore, it is most applied in the countries with a relatively low price of fuel (Russia, Kazakhstan, Ukraine, etc.).

The main technical means for the implementation of the two-phase method of harvesting grain crops are swath headers, which, according to the methods of aggregation, are divided into selfpropelled, hanged-on and trailed harvesters. The most widely used are trailed swath headers, which ensure the greatest operating width and efficient use of the engine power of the aggregating tractor. However, the greatest problem in the operation of the trailed swath headers is still the lack of stability and steering ability of their movement [6]. In order to solve it, various design improvements are used, but they produce only a partial effect, causing overall complication of the designs, an undesirable increase in the consumption of metal and time for transfer into a working and a transport position. The performance of the asymmetric machine-and-tractor aggregates, particularly the construction of calculated mathematical models of their movement, as well as gaining experimental data, have been studied in the works of many scientists, such as P. Vasilenko, L. Gyachev etc. [1; 7; 8].

Besides, the object of many studies was finding the conditions under which the phenomenon of instability (lateral drag) arises due to the fact that the aggregated trailed agricultural machine creates an unwinding force (moment) for the entire machine-and-tractor aggregate. Many previously conducted theoretical and experimental investigations pursued the goal to determine this unfolding moment and to find conditions for its reduction by introducing additional devices into the design of the 
aggregate [8-9]. Conditions have been found out, both theoretically and experimentally, that reduce this unfolding moment and increase the stability and the steering ability of the asymmetrical aggregate, determined only by changing the design parameters of the trailed swath headers. Thus, it was maintained [10] that the main design parameters, which can significantly improve the path characteristics of asymmetric harvesting aggregates, are the weight of the trailed swath header and the length of its hitch bar. However, a simple increase in these design parameters leads both to a decrease in the unfolding moment, and simultaneously to an undesirable increase in the overall dimensions and material capacity of the aggregate and, accordingly, to a significant increase in the fuel consumption and a decrease in its efficiency, etc. $[11 ; 12]$. Therefore, a necessity arises to specify other conditions affecting stable and steerable movement of the asymmetric swath header machine-and-tractor aggregate.

The aim of the work is to determine experimentally the optimum values of the kinematic and design parameters of an asymmetric swath header machine-and-tractor aggregate having impact upon its stability.

\section{Materials and methods}

In the course of experimental research and production tests, a set of measuring and recording equipment and methods, as well as the existing standards for carrying out performance testing of agricultural machinery and methods for statistical processing of experimental research materials on the PC were used. In order to determine the performance and technological indicators of the swath header asymmetric machine-and-tractor aggregate, we conducted experimental investigations under field conditions. As an object of the research, the swath header ZVP-6 was applied in various variants of implementation with the maximum designed operating width of $6 \mathrm{~m}$. Tractor MTZ-82 was used as the aggregating tool. In the base variant of the trailed swath header ZVP-6, setting of the left supporting wheel of the swath header corresponded to its factory setting, and the vertical additional load of the leftmost supporting wheel was zero $(M=0)$ (Fig. 1).

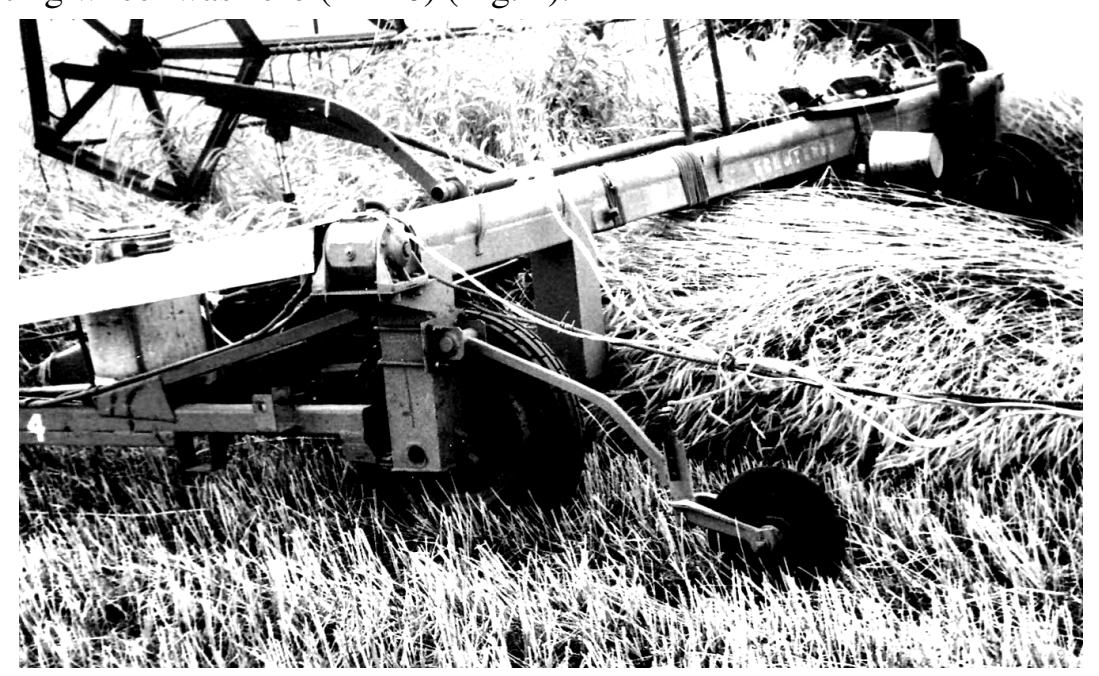

Fig. 1. Base (factory) variant of setting left supporting wheel of trailed swath header ZVP-6 (behind the left supporting wheel of the swath header there is mounted a track measuring wheel)

In other compared variants of the experimental trailed swath header the arrangement of the left supporting wheel was changed to the left of the trailed device $(0.4 \mathrm{~m}$ and $0.8 \mathrm{~m}$, the additional vertical mass $M$ from 0 to $180 \mathrm{~kg}$ ), as well as the values of the turning angles of the left $\left(\alpha_{1}\right)$ and both the right $\left(\alpha_{2}\right)$ supporting wheels in a horizontal plane were changed (Fig. 2).

In order to determine the preset parameter, we made not less than 10 measurements during the experimental research, the area of the harvested field being 240 hectares. The experimental investigations were carried out on the following agricultural background: the soil humidity at the depth of $0-15 \mathrm{~cm}$ was $10-14 \%$, the soil hardness was $2.3 \mathrm{mPa}$, the density of the wheat plants was 496 pieces $\cdot \mathrm{m}^{-2}$, the plant height $-0.86 \mathrm{~m}$. 


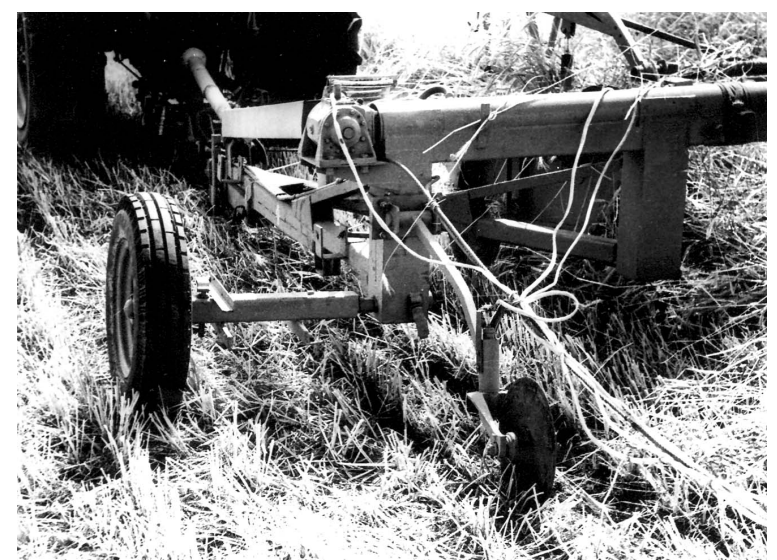

a)

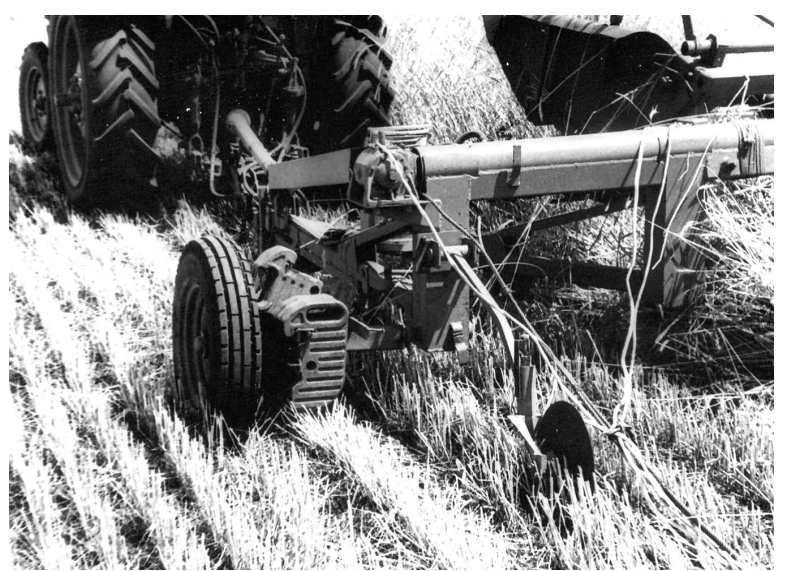

b)

Fig. 2. Experimental variant with arrangement of left supporting wheel of trailed swath header at distance (a) and with additional load (additional vertical mass on the bracket of the left wheel) - (b)

\section{Results and discussion}

The results of investigations of the dependence of the deviation angle $\beta$ of the trailed swath header in a horizontal plane, depending on the additional vertical load (mass) $M$ of its left supporting wheel at various speeds $V_{o}$ of the operating movement of the aggregate are shown in Fig. 2. The results indicate that at speed $V_{o}$ of the forward operating movement of this harvesting machine-and-tractor aggregate $2.1 \mathrm{~m} \cdot \mathrm{s}^{-1}$, the turning angle $\beta$ of the trailed windrower was $8.5^{\circ}$. Increasing the speed $V_{o}$ of the forward movement of the investigated machine-and-tractor aggregate up to $3.7 \mathrm{~m} \cdot \mathrm{s}^{-1}$, the estimated indicator increased to $10^{\circ}$ (Fig. 3).

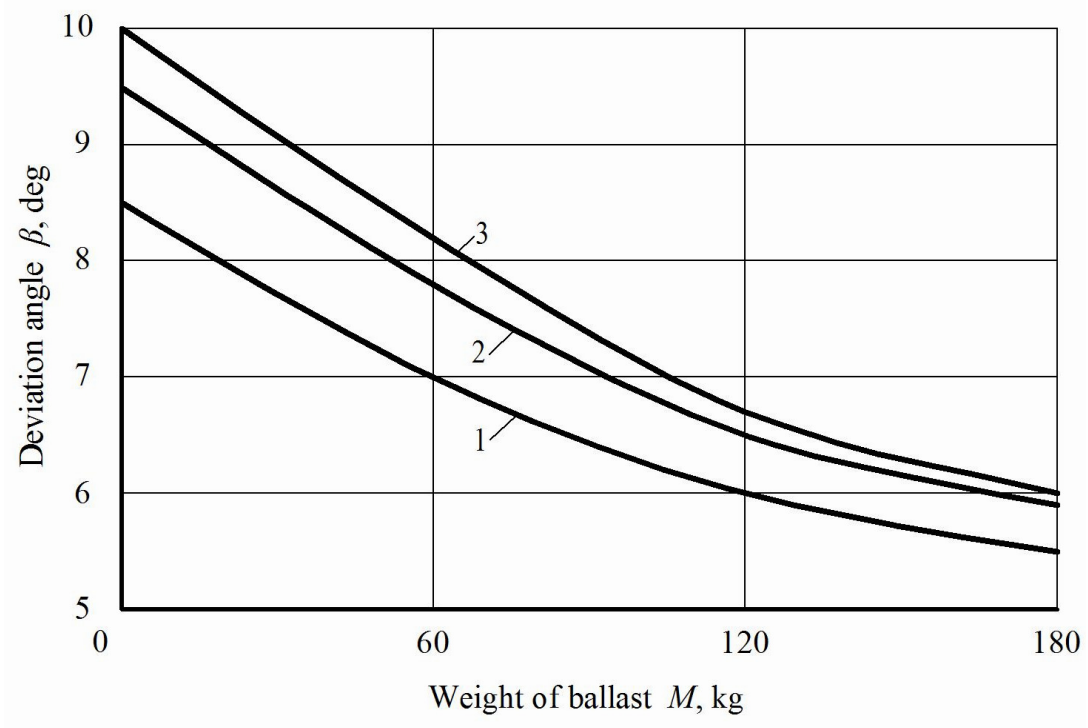

Fig. 3. Dependence of deviation angle $\beta$ of trailed swath header in horizontal plane upon value of additional load (ballasting mass) $M$ on left supporting wheel at various speeds $V_{o}$ of operating movement of aggregate: $1-2.1 \mathrm{~m} \cdot \mathrm{s}^{-1} ; 2-2.8 \mathrm{~m} \cdot \mathrm{s}^{-1} ; 3-3.7 \mathrm{~m} \cdot \mathrm{s}^{-1}$

When the additional vertical mass (AVM) on the left supporting wheel of the swath header is increased, the value of its deviation angle in a horizontal plane decreases. Nevertheless, as the load increases, the intensity of this decrease diminishes.

For instance, at speed $V_{o}$ of the movement of the particular machine-and-tractor aggregate, equal to $2.1 \mathrm{~m} \cdot \mathrm{s}^{-1}$, and at an increase in the ballasting mass of the left supporting wheel of the swath header from zero to $60 \mathrm{~kg}$, the value of angle $\beta$ decreases by $1.4^{\circ}$ (Curve 1, Fig. 2). If the additional vertical mass is increased on the left support wheel of the trailed swath header within the range from 120 to $180 \mathrm{~kg}$, the reduction of the deviation angle $\beta$ of the swath header does not exceed $0.5^{\circ}$. 
The growth of the forward speed $V_{o}$ of the operating movement of the considered harvesting unit leads to the increase in the deviation angle $\beta$ of the trailed swath header. Just in the same way, as the speed conditions increase, both the range width and the reduction intensity of angle $\beta$ have a steady tendency to decrease. For example, for $M=0$, a change in the speed from 2.1 to $3.7 \mathrm{~m} \cdot \mathrm{s}^{-1}$ corresponds to the increase in the angle $\beta$ of approximately $1.6^{\circ}$. At the same time, at $M=180 \mathrm{~kg}$ this increase constitutes only $0.5^{\circ}$ (Fig. 3). Increasing the mass of the ballast to more than $180 \mathrm{~kg}$ will increase the stability (however, the resulting increase in the stability here is not so significant). But according to the balance of forces, along with the increase in the aggregated mass, additional energy is consumed. In this case the value of the ballast mass of $180 \mathrm{~kg}$ is a compromise option providing the necessary magnitude of the reaction force at the point of contact of the wheel with the soil and sufficient (predetermined) stability during the movement of the aggregate across the irregularities of the soil surface. At $M=180 \mathrm{~kg}$, to the increase in the operating speed $V_{o}$ of this swath header machine-andtractor aggregate by $0.7 \mathrm{~m} \cdot \mathrm{s}^{-1}$ there corresponds an increase in the angle $\beta$ by $\sim 0.4^{\circ}$, and the next increase in the speed conditions by $0.9 \mathrm{~m} \cdot \mathrm{s}^{-1}$ (i.e. from 2.8 to $3.7 \mathrm{~m} \cdot \mathrm{s}^{-1}$ ) there corresponds an increase only by $0.1^{\circ}$. The above analysis of the obtained experimental data indicates that the greater the additional vertical mass on the left supporting wheel of the trailed swath header, the less is the impact of increasing the speed $V_{o}$ of the operating movement of this harvesting machine-and-tractor aggregate upon the deviation angle $\beta$ of the trailed windrower in a horizontal plane. In this case the pressure in the tires of the supporting wheels of the trailed swath header was such that the drag resistance coefficient $k_{1}$ of the left support wheel was $30.0 \mathrm{kN} \cdot \mathrm{rad}^{-1}$, and the total coefficient $k_{2}$ of the two rightside supporting wheels of the header was $65.0 \mathrm{kN} \cdot \mathrm{rad}^{-1}$. The same situation arises when the distance from the left supporting wheel to the trailed device is increased to $0.4 \mathrm{~m}$ (Fig. 4) and the additional vertical mass on the left supporting wheel is raised from 60 to $180 \mathrm{~kg}$.

So, increasing the distance of the supporting wheel of the swath header to the left only by $0.4 \mathrm{~m}$, the subsequent increase in the additional load leads to diminution of the deviation angle $\beta$ of the trailed swath header in a horizontal plane (Fig. 4).

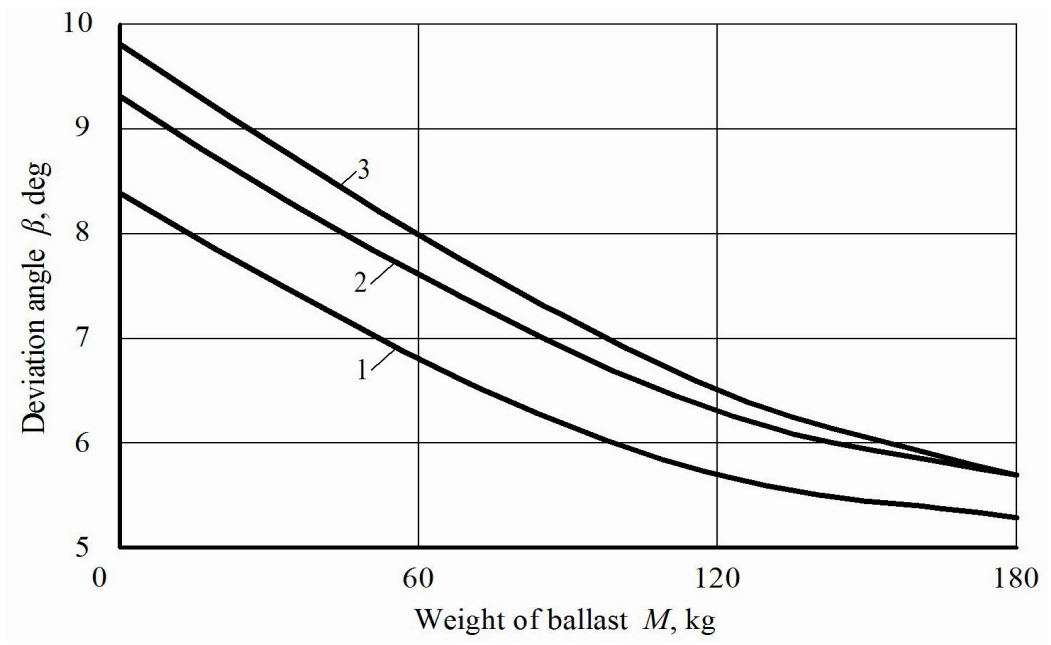

Fig. 4. Dependence of deviation angle $\beta$ of swath header in horizontal plane upon ballasting mass $M$ of its left supporting wheel, offset by $0.4 \mathrm{~m}$, and different speeds $V_{o}$ of operating movement of aggregate: $1-2.1 \mathrm{~m} \cdot \mathrm{s}^{-1} ; 2-2.8 \mathrm{~m} \cdot \mathrm{s}^{-1} ; 3-3.7 \mathrm{~m} \cdot \mathrm{s}^{-1}$

It has been established that with the increase in the speed $V_{o}$ of the movement of the swath header machine-and-tractor aggregate, the deviation angle $\beta$ of the asymmetrically trailed dynamic system increases. The same, in principle quite regular trend in the results of experimental investigations takes place also when the left supporting wheel is arranged at a distance of $0.8 \mathrm{~m}$ to the left of its trailing device (Fig. 5).

In a quantitative aspect, the impact of the value of the distance of the left supporting wheel by $0.4 \mathrm{~m}$ upon the deviation angle $\beta$ is insignificant. Increasing this parameter from 0 to $0.8 \mathrm{~m}$ without an additional vertical mass on the left supporting wheel (i. e. $M=0$ ) and at the speed $V_{o}$ of the movement $2.8 \mathrm{~m} \cdot \mathrm{s}^{-1}$ of this harvesting machine-and-tractor aggregate, the increase in the deviation angle $\beta$ of the trailed swath header under field conditions of the experiment was only $0.6^{\circ}$ (Fig. 6). 


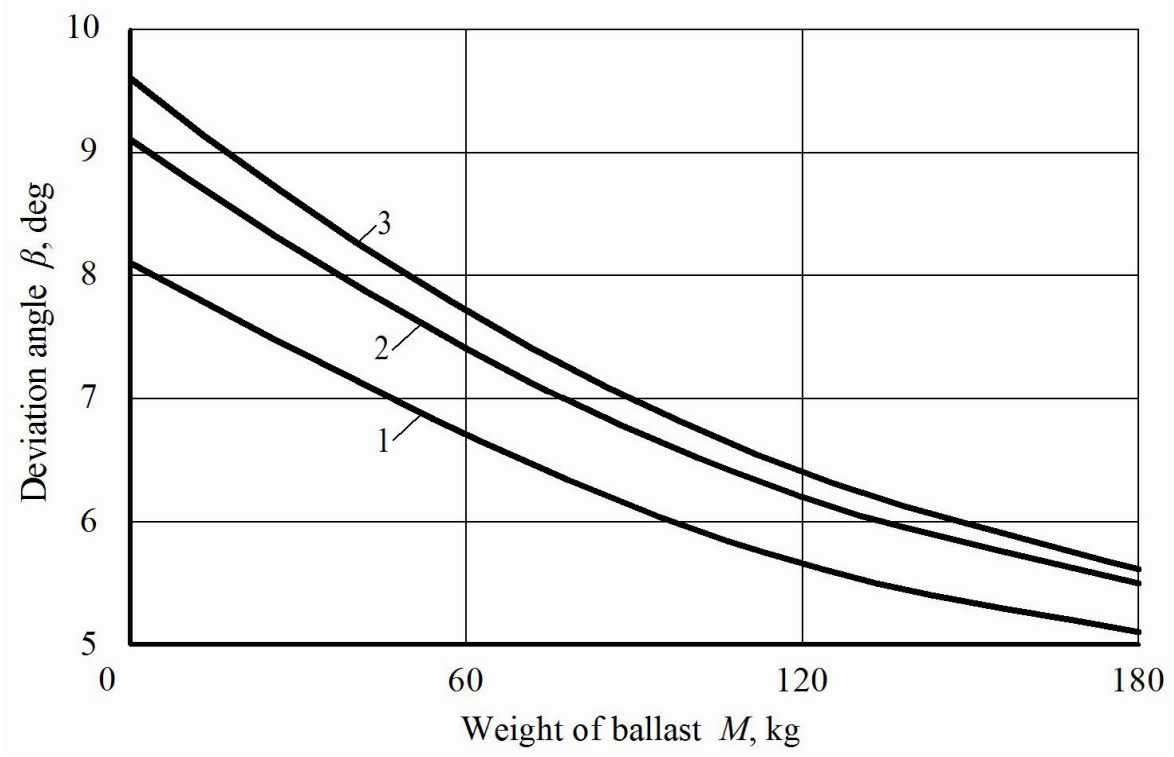

Fig. 5. Dependence of deviation angle $\beta$ of swath header in horizontal plane on value of additional vertical mass of left supporting wheel arranged at distance of $0.8 \mathbf{~ m}$ from trailing device and on various operating speeds: $1-2.1 \mathrm{~m} \cdot \mathrm{s}^{-1} ; 2-2.8 \mathrm{~m} \cdot \mathrm{s}^{-1} ; 3-3.7 \mathrm{~m} \cdot \mathrm{s}^{-1}$

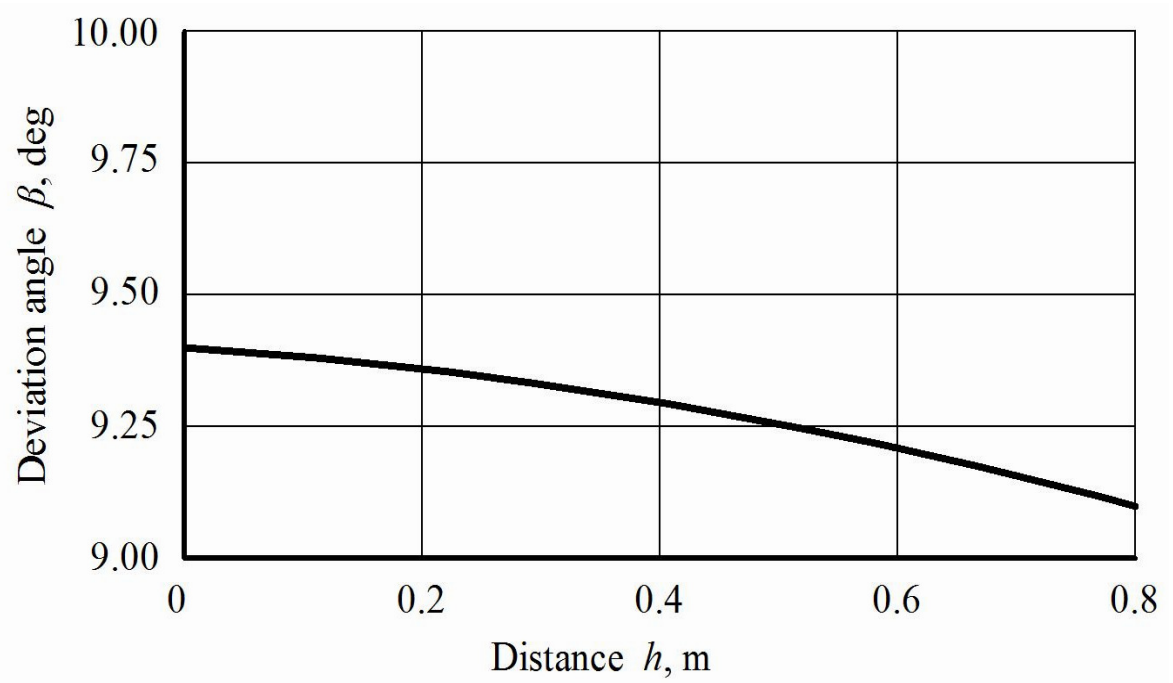

Fig. 6. Dependence of deviation angle $\beta$ of trailed swath header upon value of left-side offset (drag) $h$ of wheel at speed $V_{o}$ of aggregate $2.8 \mathrm{~m} \cdot \mathrm{s}^{-1}($ at $M=0$ )

And despite this, it is possible to make a final conclusion that the larger the additional vertical mass $M$ and the distance of the supporting wheel to the left of the swath header by $0.4 \mathrm{~m}$, the less is the impact of the increased speed of the operating movement of this aggregate upon the deviation angle $\varphi$ of the trailed swath header in a horizontal plane. It was possible to reach a significant reduction in the deviation angle $\beta$ of the asymmetric trailed swath header only at a simultaneous setting of the left and the right support wheels of the trailed asymmetrical swath header at the same angle of $8^{\circ}$ (in a clockwise direction) in relation to its rectilinear movement (Fig. 7).

As the results of long-term observations and studies of the operation of the swath headers show, the soil humidity in the layer $0-10 \mathrm{~cm}$ during the harvesting period varies within a range of $10-20 \%$. Hence it follows that to ensure the desired stability of the movement of the trailed swath header under such conditions, for various harvesting conditions its design must provide installation of the supporting wheels in a horizontal plane at angles of $0-100^{\circ}$.

The correlation coefficient of the obtained data was $16-18 \%$, which indicates a fairly high statistical stability of the results. The close coincidence percentage $(2.8-3.7 \%)$ of the theoretical and experimental studies also indicates a high reliability of the investigations. 


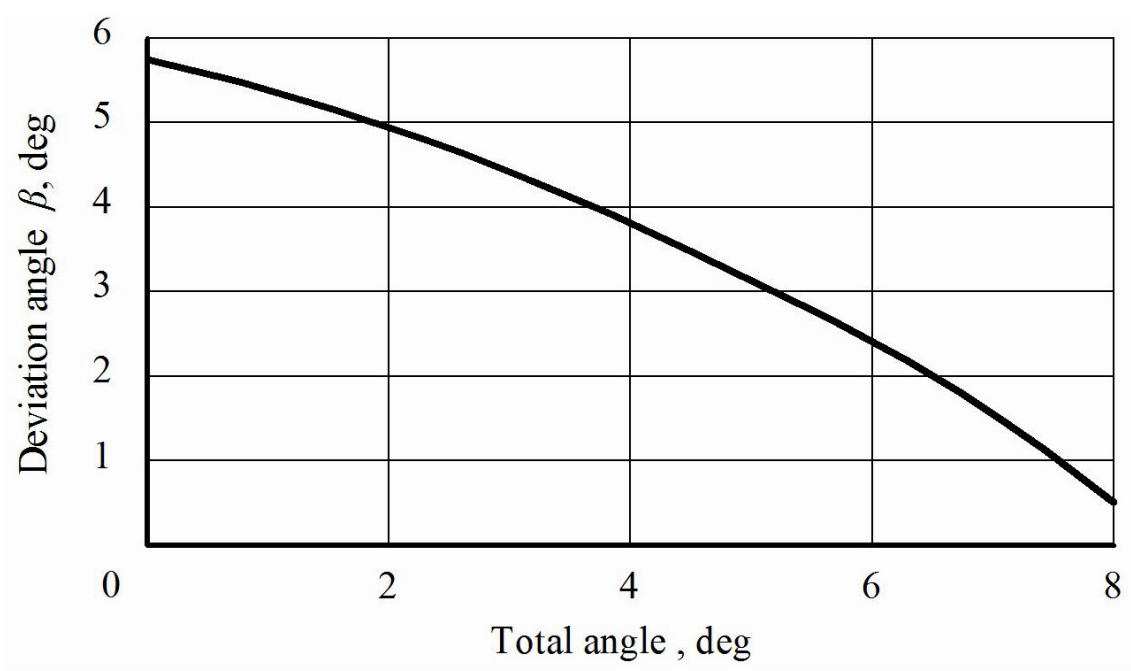

Fig. 7. Total impact of turning angles of left $\left(\alpha_{1}\right)$ and both right $\left(\alpha_{1}\right)$ support wheels of trailed swath header upon its deviation angle $\beta$ in horizontal plane, at speed $V_{o}$ of its operating movement $3.7 \mathrm{~m} \cdot \mathrm{s}^{-1}$

\section{Conclusions}

1. With the factory-made variant of setting the supporting wheels of the ZVP-6 swath header corresponding to zero values of the angles $\alpha_{1}$ and $\alpha_{2}$ of setting the supporting wheels in relation to the direction of the movement, its deviations in a horizontal plane are maximal.

2. When the supporting wheels of the trailed swath header (windrower ) are set at the angles of $8^{\circ}$ to the direction of the movement, arrangement of the left supporting wheel to the left at a distance of $0.2 \mathrm{~m}$ from the trailed device and loading it with an additional mass, equal to $1.0 \mathrm{kN}$, the drag resistance coefficients of the pneumatic tires: $k_{1}$ (of the left-side supporting wheel) equal to $30.0 \mathrm{kN} \cdot \mathrm{rad}^{-1}$ and $k_{2}$ (two right-side supporting wheels) equal to $65.0 \mathrm{kN} \cdot \mathrm{rad}^{-1}$, the header in the aggregate with a wheeled tractor in the classic layout scheme moves without deviations in a horizontal plane. This allows increasing the operating width by of $5.1 \%$ and the efficiency of the aggregate by $7.0 \%$. It is has been found that the losses of grain after the passage of such a swath header is on average 6.5 times smaller than in case the header is operated at a zero (factory) setting of the angles of its supporting wheels.

3. The greater the additional vertical mass and the distance of the left supporting wheel from the trailed device, the less is the impact of the increase in the speed of operating movement of this harvesting machine-and-tractor aggregate upon the deviation angle $\beta$ of the trailed swath header in a horizontal plane.

\section{References}

[1] Василенко П. Введение в земледельческую механику (Introduction to agricultural mechanics). Kiev, 1996. 136 p. (In Ukrainian)

[2] Надыкто В., Кюрчев В., Семенюк В., Назин А. Уборка зерновых культур раздельным способом (Harvesting of cereals), Zaporozje, 2012. 132 p. (In Ukrainian)

[3] Булгаков В., Калетник Г., Гриник И., Леженкин А. Динамика зерноуборочных агрегатов (Dynamics of the grain harvesting aggregates). Agrarian science, Kiev. 2010. 276 p. (In Ukrainian)

[4] Shinners K., Bennett R., Hoffman D. Single- and two-pass corn grain and stover harvesting. Transactions of the ASABE. Vol.55 (2), 2012, pp. 341-350.

[5] Rademacher T. Trends in the Process Technology of Grain Crop Harvesting. Agritechnica, No 6, 2003, pp.362-368.

[6] Bulgakov V., Pascuzzi S., Nadykto V. and Ivanovs S. A Mathematical model of the plane-parallel movement of an asymmetric machine and tractor aggregate. Journal of Agricultural Engineering. Vol. 49, No 1, 2018, pp. 258-271. 
[7] Гячев Л. О прямолинейном движении колесного трактора при боковом расположении навесной жатки (About rectilinear movement of a wheeled tractor with a laterally mounted reaper). Mechanization and electrification of agriculture, 6, 1979. pp.40-42 (In Russian)

[8] Bhatia, Nam Parshad; Szegő, Giorgio P. Stability theory of dynamical systems. Springer. 2002. ISBN 978-3-540-42748-3

[9] Smith, M.; Wisten, M. A continuous day-to-day traffic assignment model and the existence of a continuous dynamic user equilibrium. Annals of Operations Research, 60 (1), 1995, pp. 59-79.

[10]Гячев Л. Динамика машинно-тракторных и автомобильных агрегатов (Dynamics of the machine and tractor and automobile aggregates). Monograph, Rostov-on-Don, Russia, 1976, 192 p. (In Russian)

[11]Гуськов В. Тракторы: Теория (Tractors: Theory). Moskow, 1988. 376 p. (In Russian)

[12]Гячев Л. Stability of the movement of agricultural machines and aggregates (Устойчивость движения сельскохозяйственных машин и агрегатов). Mechanical engineering, Moscow, 1981. 206 p. (In Russian) 